\title{
ANÁLISE CRÍTICA DA SÚMULA VINCULANTE DO USO DAS ALGEMAS
}

\author{
CRITICAL ANALYSIS OF BINDING PRECEDENT \\ OF THE USE OF HANDCUFFS
}

\author{
GILBERTO SCHÄFER ${ }^{1}$ \\ DIEGO OLIVEIRA DA SILVEIRA ${ }^{2}$
}

\begin{abstract}
RESUMO: O presente estudo tem por objetivo realizar a análise da Súmula Vinculante $\mathrm{n}^{\circ} 11$ do Supremo Tribunal Federal que trata do uso de algemas. Para este desiderato buscará compreender os precedentes que deram origem ao enunciado sumular, propondo a sua classificação em 03 grupos: (a) a da afirmação da excepcionalidade, mas a de sua inaplicabilidade para o caso; (b) a utilização indevida em razão da prerrogativa da função; (c) o efeito simbólico das algemas no Tribunal do Júri. Ao fazer a análise dos precedentes e do enunciado, buscar-se-á analisar como o STF tem aplicado esta súmula e de como tem sido debatida a sua aplicação pela jurisdição ordinária, especialmente para entender os contornos de sua aplicação pelo sistema jurisdicional complementar, mostrando que a falta de amadurecimento destes precedentes tem causado uma aplicação que carece de um escrutínio mais claro.

PALAVRAS-CHAVE: Algemas; Dignidade da Pessoa Humana; Súmula Vinculante $n^{\circ} 11$ do Supremo Tribunal Federal; Reclamação Constitucional; Efetividade.
\end{abstract}

ABSTRACT: The present study aims to conduct analysis of Binding Precedent $\mathrm{n}^{\circ} 11$ of the Supreme Court dealing with the use of handcuffs. To this end seek to understand the precedents that led to sumular statement, proposing a classification into 03 groups: (a) the assertion of exceptionality, but its inapplicability to the case;

\footnotetext{
Artigo recebido em 09.03.2014. Pareceres emitidos em 15.09.2014 e 15.09.2014.

Artigo aceito para publicação em 06.10.2014.

${ }^{1}$ Mestre e Doutor em Direito Público pelo Programa de Pós-Graduação em Direito da UFRGS Universidade Federal do Rio Grande do Sul - Porto Alegre/RS. Professor dos Cursos de Graduação, Pós-Graduação e Mestrado em Direitos Humanos da UNIRITTER - Centro Universitário Ritter dos Reis - Canoas/RS. Juiz de Direito do Estado do Rio Grande do Sul, Vice-Presidente Administrativo da Associação dos Juízes do Rio Grande do Sul (AJURIS).schafer@via-rs.net ${ }_{2}^{2}$ Mestre em Direito no Curso de Direitos Humanos da UNIRITTER - Centro Universitário Ritter dos Reis - Canoas/RS. Diretor Executivo do IBDFAM/RS - Instituto Brasileiro de Direito de Família - Seção Rio Grande do Sul. Advogado Militante no Direito de Família, Sócio Efetivo do IARGS - Instituto dos Advogados do Rio Grande do Sul e Coordenador da Comissão Especial de Direitos Humanos do Instituto Proteger.
} 
(b) unauthorized use due to the prerogative of the function; (c) the symbolic effect of the Jury Court in handcuffs. By doing the analysis of precedents and the statement, will be seeking to analyze how the Supreme Court has applied this precedent and as has been discussed its application by ordinary jurisdiction, especially to understand the contours of your application by the supplementary judicial system, showing that the lack of maturity of these precedents has caused an application that needs a clearer scrutiny.

KEYWORDS: Handcuffs; Human Dignity; Binding Precedent Paragraph 11 of the Supreme Court; Constitutional Complaint; Effectiveness.

SUMÁRIO: Introdução; 1. A Inserção das Súmulas Vinculantes no Direito Brasileiro; 2. As Algemas no STF: dos precedentes à Súmula Vinculante 11; 3. A Aplicabilidade da Súmula das Algemas; Considerações Finais; Referências Bibliográficas.

SUMMARY: Introduction; 1. The Inclusion of Binding Precedents in Brazilian Law; 2. Handcuffs in the Supreme Federal Court: from case law to the Binding Precedent \#11; 3. The Applicability of the Handcuff Binding Precedent; Final Remarks; Bibliographical References.

\section{INTRODUÇÃO}

O sistema de súmulas vinculantes, introduzido pela Emenda Constitucional $n^{\circ} 45 / 2004$, reforça e supera o papel ativo já exercido pelo STF $^{3}$ na jurisdição realizada em controle abstrato, permitindo que sejam editados enunciados que terão efeito vinculante para os demais órgãos do Poder Judiciário e para a administração pública ${ }^{4}$.

O presente estudo tem a finalidade de realizar uma análise crítica da Súmula Vinculante $11^{5}$ que trata do uso de algemas, investigando os seus efeitos e sua aplicação. Para tanto, serão utilizados como vetores os valores constitucionais da preservação da segurança pública, da segurança pessoal,

\footnotetext{
${ }^{3}$ O STF superou o papel de um mero legislador negativo, como se pode ver no julgamento de casos paradigma como as células tronco, fidelidade partidária, uniões homoafetivas, que acabaram fortalecendo o chamado ativismo do Supremo Tribunal Federal.

${ }^{4}$ Neste sentido Oscar Vilhena utiliza o termo Supremocracia: "Apenas em 2005, com a adoção da súmula vinculante, completou-se um ciclo de concentração de poderes nas mãos do Supremo, voltado a sanar sua incapacidade de enquadrar juízes e tribunais resistentes às suas decisões. Assim, supremocracia diz respeito, em primeiro lugar, à autoridade recentemente adquirida pelo Supremo de governar jurisdicionalmente (rule) o Poder Judiciário no Brasil. Neste sentido, finalmente o Supremo Tribunal Federal tornou-se supremo. No caso específico, o " $\mathrm{s}$ " minúsculo do adjetivo vale mais que o "S" maiúsculo que convencionalmente reservamos aos órgãos máximos da República para demonstrar este incremento de poderes" VIEIRA, Oscar Vilhena. Supremocracia. Revista Direito GV, São Paulo 4(2), p. 441-464, jul./dez. 2008, p. 445.

${ }^{5}$ Súmula Vinculante no 11 do STF - "Só é lícito o uso de algemas em casos de resistência e de fundado receio de fuga ou de perigo à integridade física própria ou alheia, por parte do preso ou de terceiros, justificada a excepcionalidade por escrito, sob pena de responsabilidade disciplinar, civil e penal do agente ou da autoridade e de nulidade da prisão ou do ato processual a que se refere, sem prejuízo da responsabilidade civil do Estado."
} 
da incolumidade das pessoas e de seu patrimônio; de outro, os princípios da dignidade humana ${ }^{6}$ e da presunção de inocência ${ }^{7}$.

O presente artigo investigará os precedentes que deram origem à referida súmula vinculante e o modo como a questão das algemas tem reaparecido no STF, especialmente por meio da reclamação constitucional, o instrumento por excelência do efeito vinculante ${ }^{8}$.

Também, far-se-á uma investigação sobre a forma como a jurisdição ordinária tem discutido a questão da aplicação dessa súmula vinculante, abarcando os limites e as potencialidades da proteção contra o uso indevido das algemas. No mesmo sentido, proceder-se-á uma averiguação do escrutínio realizado quanto aos elementos necessários para a colocação de algemas no preso, bem como da aplicação das sanções cominadas pele enunciado vinculante para o uso indevido das algemas, especialmente na seara da nulificação dos feitos.

\section{A INSERÇÃO DAS SÚMULAS VINCULANTES NO DIREITO BRASILEIRO}

No Direito brasileiro, há um histórico de edição de súmulas, pois já havia a prática de editar e aplicar súmulas - sem qualificativo - nominadas de não vinculantes ou ordinárias ${ }^{9}$. Também havia uma prática de um efeito vinculante - em ações do controle concentrado - que nominaremos para todos os fins de uma obrigatoriedade reforçada, cujo mecanismo para impor o seu cumprimento é a reclamação ${ }^{10}$.

As súmulas qualificadas como não vinculantes, inicialmente eram concebidas apenas com um caráter persuasivo, seja do ponto de vista vertical - todos os demais juízes ou tribunais - , seja do ponto de vista horizontal ao próprio órgão julgador. A superação desse caráter persuasivo, entretanto, logo se fez sentir: as súmulas passaram a contar com instrumentos que potenciavam os seus efeitos, como a possibilidade de o relator utilizá-las para dar ou negar provimento em decisão monocrática a um recurso, excluir o

\footnotetext{
${ }^{6}$ Artigo $1^{\circ}$, III da CF/88 - "A República Federativa do Brasil, formada pela união indissolúvel dos Estados e Municípios e do Distrito Federal, constitui-se em Estado Democrático de Direito e tem como fundamentos: ...omissis... III - a dignidade da pessoa humana;"

${ }_{7}$ Artigo $5^{\circ}$ da CF/88 - "Todos são iguais perante a lei, sem distinção de qualquer natureza, garantindo-se aos brasileiros e aos estrangeiros residentes no País a inviolabilidade do direito à vida, à liberdade, à igualdade, à segurança e à propriedade, nos seguintes termos: ...omissis... LVII - ninguém será considerado culpado até transito em julgado de sentença penal condenatória;"

${ }^{8}$ MENDES, Gilmar Ferreira; COELHO, Inocêncio Mártires; BRANCO, Paulo Gustavo Gonet. Curso de Direito Constitucional. 4. ed., São Paulo: Saraiva, 2009. p. 1.346.

${ }_{9}$ SCHÄFER, Gilberto. Súmulas Vinculantes - Análise crítica da experiência do Supremo Tribunal Federal. Porto Alegre: Livraria do Advogado, 2012. p. 20.

${ }^{10}$ ZAVASCKI, Teori Albino. Eficácia das Sentenças na Jurisdição Constitucional. São Paulo: Revista dos Tribunais, 2001. p. 53: Nas palavras de Zavascki, "o Efeito Vinculante confere ao julgado um força obrigatória qualificada, com a conseqüência processual de assegurar, em caso de recalcitrância dos destinatários, a utilização de um mecanismo executivo - a reclamação - para impor o seu cumprimento.
} 
reexame necessário, quando a decisão estivesse de acordo com o sumulado pelos Tribunais Superiores ou então para deixar de receber uma apelação, quando a decisão recorrida estivesse de acordo com a súmula não vinculante ${ }^{11}$.

No entanto, se o tribunal ou juízo a quo decidisse não aplicar a súmula não-vinculante, não haveria - e não há - a obrigatoriedade de segui-la, porque o enunciado não possuía - e não possui - efeito vinculante em sentido próprio.

As súmulas vinculantes foram inseridas no ordenamento pelo artigo $103-\mathrm{A}^{12}$ e regulamentadas, dois anos depois, pela Lei $n^{\circ} 11.417 / 2006$. Segundo essa conjugação normativa, a súmula poderá ser editada de ofício ou mediante provocação ${ }^{13}$, unicamente, pelo Supremo Tribunal Federal. Há a previsão de que ela somente seja editada - também revisada ou cancelada - art. $4^{\circ}$ da Lei 11.417/2006 - por dois terços dos membros do STF, após reiteradas decisões sobre matéria constitucional, cujo enunciado terá efeito vinculante aos demais órgãos do Poder Judiciário e à administração pública direta e indireta, nas esferas federal, estadual e municipal. Não há efeito vinculante direto para o poder legislativo em sua esfera típica ${ }^{14}$.

As súmulas vinculantes serão expedidas em matéria constitucional sobre a validade, a interpretação ou a eficácia de determinada norma, acerca da qual haja controvérsia atual entre órgãos do Poder Judiciário ou entre esses e a administração pública que acarrete grave insegurança jurídica e relevante multiplicação de processos sobre questão idêntica, afirmando a supremacia da constituição. ${ }^{15}$ Elas visam buscar a igualdade - para casos iguais haverá idêntica decisão - e segurança jurídica, na sua roupagem de previsibilidade, evitando a aplicação controvertida do Direito entre órgãos judiciais ou entre estes e administração pública.

\footnotetext{
${ }^{11}$ Ver: Artigos 557, caput e $\S 1^{\circ}$-A; 475, $\S 3^{\circ}$ e 518, $\S 1^{\circ}$ do Código de Processo Civil, respectivamente.

${ }_{12}$ Artigo 103-A da CF/88 - "O Supremo Tribunal Federal poderá, de ofício ou por provocação, mediante decisão de dois terços dos seus membros, após reiteradas decisões sobre matéria constitucional, aprovar súmula que, a partir da sua publicação na imprensa oficial, terá efeito vinculante em relação aos demais órgãos do Poder Judiciário e à administração pública direta e indireta, nas esferas federal, estadual e municipal, bem como proceder à sua revisão ou cancelamento, na forma estabelecida em lei."

${ }^{13}$ Além do Supremo Tribunal Federal poder de ofício editar, revisar e cancelar as súmulas vinculantes, o artigo 103-A, § $2^{\circ}$ da Constituição Federal da 1988 previu que podem provocar a edição, revisão e cancelamento dessas súmulas os mesmos legitimados ${ }^{13}$ para propor as ações do controle concentrado de constitucionalidade. A Lei das Súmulas Vinculantes acrescentou a esse rol $^{13}$ o Defensor-Público da União e os Tribunais (Superiores, Tribunais de Justiça, TRF`s, TRT`s, TRE`s e Tribunais Militares). Acrescenta-se, ainda, aos legitimados previstos no caput do artigo $3^{\circ}$ da Lei das Súmulas Vinculantes o município, pois ele poderá propor, incidentalmente ao curso de processo em que seja parte, a edição, revisão ou cancelamento de enunciado de súmula, mas isso não acarreta a suspensão do processo, conforme prevê o $\S 1^{\circ}$ do dispositivo legal supra referido. Logo, os legitimados para propor a edição das súmulas são amplos, o que vem democratizar o instituto das Súmulas Vinculantes.

${ }^{14}$ SCHÄFER, Gilberto. Súmulas Vinculantes - Análise crítica da experiência do Supremo Tribunal Federal. Porto Alegre: Livraria do Advogado, 2012. p. 102-103.

${ }^{15}$ SCHÄFER, Gilberto. Súmulas Vinculantes - Análise crítica da experiência do Supremo Tribunal Federal. Porto Alegre: Livraria do Advogado, 2012. p. 35-39.
} 


\section{AS ALGEMAS NO STF: DOS PRECEDENTES À SÚMULA VINCULANTE 11}

As algemas ${ }^{16}$ eram utilizadas para prender pelos pulsos, e os grilhões para jungir os tornozelos dos presos ${ }^{17}$, mas as algemas não eram apenas um meio de submeter fisicamente o preso, senão também uma forma de castigo, pois quem fosse visto usando algemas era considerado um bandido ${ }^{18}$ e uma pessoa perigosa ${ }^{19}$. O Direito Penal e o Direito Processual Penal, conforme Carnelutti, utilizam esse ícone para realizar uma violência simbólica contra esta pessoa que é perigosa ${ }^{20}$.

As algemas representam para o Direito Penal, além de um instrumento de força - impedir a fuga do preso -, uma forma de repressão e de coerção do Estado, tornando-se, muitas vezes, o símbolo maior de humilhação do homem. ${ }^{21}$

A algema "não é um mero instrumento do trabalho policial", tendo em vista a imagem de perigo e estigma que passa para a sociedade ${ }^{22}$. Assim 0 uso de algemas ao menos para uma pessoa que não apresente risco de fuga ou de lesão a terceiros tem consequências para a sua dignidade, pois o indivíduo que está algemado é visto como alguém perigoso, que feriu um bem jurídico protegido pelo ordenamento e que, por isso, merece ser punido por essa conduta, no que resta afetada a sua estima e honra ${ }^{23}$.

Admite-se utilizar as algemas apenas em caráter excepcional, conforme a disposição da Súmula Vinculante 11 do STF que se insere neste quadro. Ela foi editada em 13 de agosto de 2008, com o seguinte teor:

${ }^{16}$ PITOMBO, Sérgio Marcos de Moraes. Emprego de Algemas - notas em prol de sua regulamentação. Revista dos Tribunais, São Paulo, v. 592, p. 275-292, fev. 1985, p. 275: A palavra "algema" é proveniente do árabe aljamaa, que significa "a pulseira", surgindo dita palavra no sentido de aprisionar somente no século XVI. Em tempos mais remotos, todo o instrumento capaz de prender as mãos era chamado de "cadeias", de "ferros" ou de "grilhões".

17 PITOMBO, Sérgio Marcos de Moraes. Emprego de Algemas - notas em prol de sua regulamentação. Revista dos Tribunais, São Paulo, v. 592, p. 275-292, fev. 1985, p. 275.

18 PITOMBO, Sérgio Marcos de Moraes. Emprego de Algemas - notas em prol de sua regulamentação. Revista dos Tribunais, São Paulo, v. 592, p. 275-292, fev. 1985, p. 280.

19 CARNELUTTI, Francesco. As Misérias do Processo Penal. Traduzida por José Antônio Cardinalli. 6. ed., Campinas: Bookseller, 2005. p. 26.

${ }^{20}$ CARNELUTTI, Francesco. As Misérias do Processo Penal. Traduzida por José Antônio Cardinalli. 6. ed., Campinas: Bookseller, 2005. p. 24: "As algemas, também as algemas são um símbolo do direito; quiça, a pensar-se, o mais autêntico de seus símbolos, ainda mais expressivo que a balança e a espada. (...) E justamente as algemas servem para descobrir o valor do homem, que é, segundo um grande filósofo italiano, a razão e a função do direito. (...) Aquilo que estava escondido, na manhã na qual vi o homem lançar-se contra o outro, sob a aparência de fera, era o homem: tão logo ataram seus pulsos com a corrente, o homem reapareceu; o homem como eu, com o seu mal e com o seu bem, com as sombras e com a suas luzes, com a sua incomparável riqueza e sua espantosa miséria".

${ }^{21}$ VIERA, Luís Guilherme. Algemas: uso e abuso. Revista Síntese de Direito Penal e Processual Penal. São Paulo, no 16, p. 11-16, out./nov. 2002, p. 15.

22 PITOMBO, Sérgio Marcos de Moraes. Emprego de Algemas - notas em prol de sua regulamentação. Revista dos Tribunais, São Paulo, v. 592, p. 275-292, fev. 1985, p. 280.

${ }_{23}$ THOMÉ, Liane Maria Busnello. Dignidade da Pessoa Humana e Mediação Familiar. Porto Alegre: Livraria do Advogado, 2010. p. 45. 
Só é lícito o uso de algemas em casos de resistência e de fundado receio de fuga ou de perigo à integridade física própria ou alheia, por parte do preso ou de terceiros, justificada a excepcionalidade por escrito, sob pena de responsabilidade disciplinar, civil e penal do agente ou da autoridade e de nulidade da prisão ou do ato processual a que se refere, sem prejuízo da responsabilidade civil do Estado.

Percebe-se que o enunciado não proíbe o uso de algemas, quando excepcionalmente necessário, pois busca sopesar os princípios da dignidade da pessoa humana e da presunção de inocência com o princípio da segurança pública $^{24}$ na aplicação da regra que permite utilizar as algemas. Nesse sopesamento, deve-se considerar o histórico de estigma deste instrumento, e o entendimento de que ele não seja utilizado desnecessariamente, sob pena de ferir a dignidade do preso.

Os ideais iluministas de liberdade e de igualdade de todos perante a lei conduziram ao reconhecimento do direito de todo e qualquer indivíduo ser presumido inocente até que seja declarado culpado ${ }^{25}$. A presunção de inocência possui um valor ideológico que deve orientar o legislador a garantir a posição de liberdade do acusado diante do interesse coletivo da repressão penal, enquanto não houver uma decisão condenatória transitada em julgado ${ }^{26}$, e se contrapõe à concepção absolutista de que o acusado tem que comprovar a sua inocência ${ }^{27}$.

O uso das algemas gera socialmente a impressão de culpa e de periculosidade da pessoa que está algemada; consequentemente, o uso injustificado desse instrumento afronta a presunção de inocência, pois se retoma a presunção de culpa que imperava na Idade Média.

O uso das algemas deve ser excepcional, e essa situação deve ser justificada por escrito, ou seja, devidamente motivada ${ }^{28}$, sob pena de

\footnotetext{
${ }^{24}$ Sobre a ponderação ver: ALEXY, Robert. Teoria dos Direitos Fundamentais. Traduzida por Virgílio Afonso da Silva, 2. ed., São Paulo: Malheiros, 2011. p. 286-287.

${ }^{25}$ GUEDES, Clarissa Diniz. Presunção de Inocência, Liberdade de Expressão e Direito à Informação: reflexões à luz da jurisprudência do Tribunal Europeu de Direito Humanos e da Corte Americana de Direitos Humanos. Revista Forense, Rio de Janeiro: Forense, vol. 411, set./out. 2010. p. 04.

${ }^{26}$ GOMES FILHO, Antonio Magalhães. Presunção de Inocência e Prisão Cautelar. São Paulo: Saraiva, 1991. p. 37.

${ }^{27}$ GUEDES, Clarissa Diniz. Presunção de Inocência, Liberdade de Expressão e Direito à Informação: reflexões à luz da jurisprudência do Tribunal Europeu de Direito Humanos e da Corte Americana de Direitos Humanos. Revista Forense, Rio de Janeiro: Forense, vol. 411, set./out. 2010. p. 04.

28 "É de significativa importância demonstrar-se, conceitualmente, o que se entende por 'decisão, motivação, fundamentação e justificação', como o que, ao fim, se evidenciará que essas expressões, muito embora sejam utilizadas como sinônimas, apresentam diferenças substanciais entre si. Impende se observar, nessa perspectiva, que o motivo representa a causa ou a condição de uma decisão, isto é, de uma escolha de uma alternativa, que se apresenta como a melhor para a solução do caso, a qual serve para direcionar a atividade para um fim específico; o fundamento, de sua vez, é a explicação ou a justificação racional que permite compreender a razão pela qual uma decisão foi ditada em um sentido, e não em outro. Vê-se, assim, que a motivação é a explicação dos motivos do provimento judicial, ou seja, se constitui no instrumento que orienta a explicação da decisão;
} 
responsabilização do agente encarregado da prisão nas esferas disciplinar, civil e penal, sem embargo da responsabilidade civil do Estado e da nulidade do ato que se refira à prisão.

Aponta-se que o Supremo Tribunal Federal utilizou, para embasar a súmula vinculante da limitação do uso das algemas, alguns julgados que haviam reconhecido o abuso na prisão. Mas qual é a identidade dos casos julgados pelo STF? Inicialmente parece que a identidade seja algo simples de se evidenciar em cada julgamento, mas em todo o precedente há uma possibilidade de um olhar mais generalizante ou restritivo. Podemos problematizar esta asserção com a hipótese de um professor que aceita que um aluno faça a prova em data especial em decorrência do falecimento da mãe. Caso quiséssemos fazer um enunciado sumular com base nesse caso, como ele seria formulado?

Poderíamos fazer as seguintes tentativas de formulá-lo29: (a) "Em caso de falecimento da mãe, o aluno terá prova em data especial" (b) "Em caso de falecimento dos pais, o aluno terá prova em data especial"; (c) "Em caso de falecimento de pessoa da família, o aluno terá prova em data especial". (d) "Em caso de falecimento de pessoa significativa, o aluno terá prova em data especial".

Todas essas formulações envolvem escolhas. A forma (a) é a mais fiel ao caso em que o professor tomou a decisão de justificar a ausência. Mas é a mais restrita de todos. Certamente, se falecesse o pai, o precedente mostraria a sua insuficiência.

Então, a forma (b) apresenta uma vantagem em relação à forma apresentada em (a). No entanto, caso ocorresse o falecimento de um irmão, da avó, como proceder? O enunciado na forma (c) teria a vantagem de incluir essas pessoas, mas utiliza um conceito que precisaria ser delimitado: o significado de família. Esse é um conceito que possui uma abertura normativa maior e mesmo um uso que pode ser amplo ou restrito, dependendo, inclusive, do contexto social envolvido. Certamente, o intérprete e aplicador em questões posteriores seria chamado a fazer delimitações necessárias para a sua concreção. No entanto, se ocorresse o falecimento do melhor

ao passo que a fundamentação é a justificação racional capaz de explicar porque se está procedendo de determinada maneira. Enfim é possível dizer-se que motivar é dizer quais as bases fáticas e/ou de direito que permitem a fundamentação, ou seja, a explicação racional da decisão". Logo, quando o julgador fundamenta uma decisão penal o mesmo deve motivar a mesma utilizando os fatos daquele preso e não circunstâncias genéricas do tipo penal, sob pena de assim não proceder ensejar a ausência/deficiência da motivação. Ver: SCHEID, Carlos Eduardo. A Motivação das Decisões Penais a partir da Teoria Garantista. Porto Alegre: Livraria do Advogado, 2009, p. 107-108.

${ }_{29}$ Exemplos semelhantes de demonstração deste raciocínio se encontram em SCHAUER, Frederick. Precedent. Stanford Law Review, fev. 1987. Disponível em: <http://www.gvpt.umd.edu/ CITE-IT/Documents/Schauer\%201987\%20Precedent.pdf>. Acesso em: 20 nov. 2013 e SILVA, Celso Albuquerque. Do Efeito Vinculante: sua legitimação e aplicação. Rio de Janeiro: Lumen Juris, 2005, p. 190 e seguintes. 
amigo do aluno, aquele que é seu confidente, com o qual ele tem uma relação especial, estaria justificada a ausência? O único enunciado em que a ausência estaria justificada seria o (d), mas com o risco de justificar qualquer ausência em decorrência de falecimento. Nessa última forma, certamente, haveria a incidência de todas as objeções à extrema abertura, que permitiria justificar todas as ausências em caso de falecimento de pessoas das relações do aluno.

Considerando a forma de enunciar com base em um único caso, percebe-se que a Constituição Federal exigiu que a súmula vinculante seja expedida somente após "reiteradas decisões" sobre "matéria idêntica". Reiteradas decisões significa, de antemão, poder identificar o caso e procurar, no passado, a generalização necessária para a futuridade ${ }^{30}$, ou seja, apesar do caráter acessório ${ }^{31}$ ou subordinado ${ }^{32}$ em relação aos textos anteriores, as súmulas são transformadas em texto que remetem a um programa normativo para casos futuros.

As súmulas vinculantes são textos que são transformados em norma ${ }^{33}$ - sem descurar, como se destacou aqui, que essa interpretação exige uma

\footnotetext{
${ }^{30} \mathrm{Na}$ expressão de Friedrich Müller, "a futuridade (Zukünftigkeit)". Ver: MÜLLER, 2005, op. cit., p. 49.

${ }^{31}$ Jorge Miranda acentua este ponto da acessoriedade, quando se refere ao instituto dos assentos, embora para chegar a resultado diverso da posição que assumimos aqui: "Numa primeira fase, escrevemos que o assento possuía uma eficácia geral sem ser normativa; que aí se executava uma norma; que não havia um limite que surgisse novo, havia uma questão que se decidia à luz do Direito, já existente. Depois abandonamos essa maneira de ver, para, pura e simplesmente, descortinarmos nele um acto normativo da função jurisdicional. Não se tratava de normas legislativas nem de interpretação autêntica em acepção própria; faltava-lhe o irrescusável elemento político que nestas sempre se exibe. Tratava-se, sim, de normas jurisprudenciais, o que explicava a sua necessária acessoriedade perante a lei a que correspondiam, bem como as limitações da sua emanação. Nem se outorgava ao tribunal pleno por fixar doutrina um poder de direcção dos tribunais contrário à sua independência; ele não procedia senão à formulação de uma proposição - não de todas as preposições do juízo jurisprudencial". Ver: MIRANDA, Jorge. Manual de Direito Constitucional: actividade constitucional do Estado. T. 5, Coimbra: Coimbra Editora, 2000. p. 42.

${ }^{32}$ Para João José Leal e Pedro Roberto Decomain, as súmulas têm caráter subordinado. Os autores partem da noção de norma de reconhecimento para chegar até tal finalidade: "Naturalmente que a Súmula do Tribunal Superior constituirá regra de reconhecimento subordinada. Se surgir norma emanada do Poder Legislativo com conteúdo diverso daquele inerente à súmula, esta deverá ser considerada tão revogada quanto o seria uma outra lei anterior que tivesse conteúdo destoante daquele da lei nova". Ver: LEAL, João José; DECOMAIN, Pedro Roberto. Súmula Vinculante, Regras de Reconhecimento e Textura aberta do Direito. Resenha Eleitoral, v. 11, $\mathrm{n}^{\circ}$ 1, p. 39, jan./jun. 2004.

${ }^{33}$ Neste sentido, a lição de Arruda Alvim que se refere ao sistema anterior à EC/45; em linguagem diversa da adotada neste texto, expressa: "As Súmulas têm conteúdo eminentemente jurídico, consistente na interpretação do Direito, tal como tenha sido objeto de julgamento pelo STF ou outro Tribunal, e, em face da Constituição Federal de 1988, tudo indica a edição de súmulas pelo Superior Tribunal de Justiça, que terão notável influência em nosso Direito. Geralmente, a Súmula é enunciada quando a jurisprudência já se encontra assentada, em um determinado sentido. Súmula, portanto, é representativa de uma expressão lingüística, geralmente com teor sintético de uma corrente jurisprudencial, tida como a correta na interpretação da lei. Confere à situação de dubiedade, existente diante de dualidade, ou mais, de entendimentos jurisprudenciais, o atributo
} 
maior vinculação com a sua genética, na qual se buscam os seus motivos determinantes. Na busca do seu sentido, deve-se levar em conta que a solução eleita - transformada em súmula - entre as possíveis - está ligada a uma controvérsia anterior, que também demarca o seu espaço de pré-compreensão. A súmula, considerada como norma, pode ser mais aberta ou mais fechada ${ }^{34}$, dependendo do seu texto, e deve expressar o âmbito em que a norma de decisão jurisdicional foi produzida - sob pena de ferir o Texto Constitucional. Com base nessa problemática se enfrentará a genética dos casos em que foi expedida a Súmula Vinculante 11 para compreender a chamada "identidade dos casos" e verificar quais sãos os critérios gerais para a adoção de conduta que o STF comunica para o futuro.

Ao analisar os precedentes ${ }^{35}$ que deram origem aos acórdãos, podemos dividi-los em três grupos: (a) o da afirmação da excepcionalidade, com a

da certeza através da eleição privilegiada do entendimento havido como o correto. Quer pelo Enunciado em si mesmo, quer por esse atributo de privilegiar um dos entendimentos. Confere maior certeza ao Direito. As súmulas, muitas vezes serão um desdobramento de uma norma, com outra linguagem, descritiva de uma implicação constante e particular da norma, em um quadro sistemático em que é assim aplicada. Estas serão representativas de uma explicitação rigorosamente interpretativa da significação da norma, total ou parcialmente considerada; nestes casos, ter-se-á agregado ao Enunciado Sumular um caráter revelador de uma hipótese praticamente relevante, contida nessas normas, o que representará, então, papel esclarecedor na inteligência do Direito voltado à sua aplicação". Ver: ALVIM, Arruda. Tratado de Direito Processual Civil. 2. ed., refundida do Código de Processo Civil comentado. v. 1 (Arts. $1^{\circ}$ ao $6^{\circ}$ ). São Paulo: Editora Revista dos Tribunais, 1990. p. 17.

${ }^{34}$ Ver: ALVIM, loc. cit. Arruda Alvim refere este aspecto da generalidade, dependente da norma anterior trabalhada: "o âmbito da generalidade da Súmula dependerá de ela estar sobreposta a toda a norma, ou não. Por outro lado, a Súmula 152, 'revogada', pela 494, inclusive esta, são ambas, v.g., o resultado de uma interpretação sistemática, compreensiva de mais de um texto, com vistas a identificar qual o prazo prescricional da lesão, tendo em vista a proibição do Art. 1.132, do Código Civil. Isso demonstra que a Súmula pode representar o resultado de uma interpretação sistemática, pois a de $n^{\circ} 494$ engloba mais de um texto, explicitando uma solução contida no sistema. Ademais, demonstra que se pode corrigir um entendimento, ainda que precedentemente sumulado". Sobre a discussão a respeito da Súmula 494, assim ementada: 'A ação para anular venda de ascendente e descendente, sem consentimento dos demais, prescreve em 20 anos, contados da data do ato, revogada a Súmula no 152 ". Ver: ROSAS, Roberto. Direito Sumular: comentários às Súmulas do Supremo Tribunal Federal e do Superior Tribunal de Justiça. 8. ed., rev. e atual. São Paulo: Malheiros Editores, 1997, p. 210-217.

${ }^{35}$ No Direito Brasileiro, o precedente tem o significado de ser, em princípio, uma única decisão isolada que tem valor argumentativo e cujo prestígio dependerá da autoridade do Tribunal, do juiz que a proferiu, de sua carga argumentativa, bem como do órgão interno do Tribunal que a tomou. É importante frisar que a forma como é externado o voto dos Tribunais faz com que seja muito importante o prestígio do relator do processo no Tribunal. A decisão é formada com base em uma exposição individual - voto -, podendo ser acompanhado pelos demais integrantes do órgão julgador. Existem alguns mecanismos no Brasil em que a decisão é tomada mediante procedimentos especiais, como a unificação da jurisprudência, quando então terá uma eficácia vinculativa maior, como se demonstrará. A aplicação do procedente dependerá também se é contemporâneo aos casos que estão sendo julgados ou se já decorreu um grande lapso temporal quando foi tomado, bem como da hierarquia, ou seja, considerando a sua dimensão vertical (dimensão de autoridade). Ver: SCHÄFER, Gilberto. A Atividade de Pretor Romano: antecedentes remotos do processo de sumularização. In: Revista da AJURIS, v. 140, n 132, dez. 2013. Porto Alegre: AJURIS, p. 146-147. 
ressalva de sua inaplicabilidade para o caso; (b) o da utilização indevida em razão da prerrogativa da função; (c) o do efeito simbólico das algemas no Tribunal do Júri.

No grupo (a) os precedentes ${ }^{36}$ firmaram a tese da sua utilização devida, mas excepcional. O primeiro caso é um recurso em Habeas Corpus 56.465, julgado pelo STF em 05.07.1978, sendo relator o ministro Cordeiro Guerra e assim está ementado: "Não constitui constrangimento ilegal o uso de algemas por parte do acusado, durante a instrução criminal, se necessário a ordem dos trabalhos e a segurança das testemunhas e como meio de prevenir a fuga do preso. (...)RHC improvido." Esse precedente não indica claramente no que consistiria a necessidade para a ordem dos trabalhos e utiliza a expressão "prevenir a fuga" que é mais ampla do que o "fundado receio de fuga". Prevenir a fuga pode ter um caráter de prevenção genérico e não específico - em relação ao sujeito -, pois sempre - tomado de forma abstrata - há possibilidade de fuga. Dessa forma, sempre a utilização da algema cumpriria essa função, quando a pessoa não estivesse contida por outro sistema, como, por exemplo, as grades (algemar torna muito difícil fugir). No referido acórdão, não há indicação de atitudes perigosas e indevidas, e o crime, ao que tudo indica, pela narrativa, é um crime de falsificação, ou seja, sequer havia violência na sua consecução.

Ainda, dentro do primeiro grupo de casos, no Habeas Corpus 71.195, Segunda Turma, Rel. Min. Francisco Rezek, j. 25.10.1994, por sua vez se decidiu que o emprego de algemas em plenário do júri não constituiu constrangimento ilegal, porque havia informações de que o réu pretendia agredir o Juiz-Presidente e o Promotor de Justiça. Nesse caso, entendeu-se por preservar a indicação da ordem, da incolumidade e da periculosidade para algemar 0 acusado.

Outro grupo de casos - grupo (b) - é o ligado à prerrogativa de função. No Habeas Corpus $n^{\circ} 89.429 /$ RO, foi concedida a ordem para que um preso não fosse algemado. O remédio constitucional foi impetrado por um Conselheiro do Tribunal de Contas de Rondônia que buscava não ser algemado durante

\footnotetext{
${ }^{36}$ Súmula não é precedente", pois precedente é um caso anteriormente apreciado e julgado por um juiz ou Tribunal, ou seja, tem nome, sobrenome e individualidade. Súmulas criariam textos e precedentes concretizam normas. Ora a súmula remonta à genealogia de um caso ou conjunto de casos a partir dos quais se identificam os motivos determinantes responsáveis pela consolidação de um critério normativo generalizante, o qual, diversamente daquele verificado numa norma jurídica, foi construído mediante argumentação jurídica oriunda de atividade jurisdicional, cuja particularidade, para efeito de se sufragar uma decisão dentre outras, aponta para a elaboração da resposta constitucionalmente mais adequada, o que inclui o repúdio a alternativas decisórias possíveis à luz do texto objeto da interpretação efetuada pelo Tribunal criador da súmula. Sua expressão numa tese normativa digna de universalidade não a confunde com um texto legislativo carente de interpretação jurisdicional, porque a súmula é uma norma (produto de uma interpretação consolidada em razões determinantes) consolidada em texto. Ver: REIS, Mauricio Martins. Precedentes Obrigatórios e sua Adequada Interpretação. In: Revista do Programa de PósGraduação em Direito da Universidade Federal da Bahia, jul. 2014. Salvador: UFBA, p. 68-69.
} 
a sua condução da carceragem da Polícia Federal em Brasília ao gabinete da ministra do Superior Tribunal de Justiça - STJ, onde prestaria depoimento pessoal, pois dito conselheiro teria sido algemado em sua residência mediante exposição à imprensa de todo o país ${ }^{37}$.

Nesse mesmo sentido foram impetrados dois habeas corpus (HC 89.419/RO e HC 89.416/RO) com fundamentos idênticos, tendo como pacientes um procurador de justiça e um desembargador, respectivamente, e a Ministra Relatora Carmen Lúcia apontou que o "uso de algemas há de obedecer aos princípios constitucionais da proporcionalidade e da razoabilidade, sob pena de nulidade".

Qual seria a ratio decidendi dessas decisões? Em primeiro lugar, o STF considerou desnecessária a utilização das algemas, porque entendeu que o paciente não oferecia riscos, principalmente em razão do seu comportamento. Em segundo lugar, entende que as algemas constituem um espetáculo público, ou seja, debate a exposição dos presos, agora algemados. Mas há uma razão que é a prerrogativa do cargo, uma razão que não é geral - quanto aos destinários - mas inerente a quem ocupa determinadas funções públicas, como membros do Ministério Público e magistrados.

Finalmente, temos um terceiro grupo de casos (c) que firma a tese do impacto do uso de algemas no Tribunal do júri. Neste, a pedra de toque é periculosidade da pessoa algemada, característica que induziria a um grau elevado de certeza a respeito de autoria e materialidade ou, em outras palavras, que a pessoa apareceu contida por algemas pois assim o fez por merecer. No julgamento do Habeas Corpus no 91.952/SP impetrado por um pedreiro acusado de homicídio qualificado, foi requerida a anulação do julgamento efetuado pelo Tribunal do Júri da cidade de Laranjal Paulista em 2005, arguindo a preliminar de nulidade em virtude de o réu ter permanecido algemado durante todo o julgamento realizado no Tribunal de Júri.

O STF deferiu a ordem e tornou insubsistente a decisão do Tribunal do Júri, determinando a realização de outro julgamento com presença do réu no plenário do júri, sem o uso das algemas. Há nesse caso uma differentia em relação ao grupo anterior. O STF entendeu que é preciso ter demonstrado a periculosidade com práticas anteriores para não "colocar a defesa, antecipadamente, em patamar inferior, não bastasse a situação de todo degradante". Há um outro elemento, o fato de o julgamento no júri ser conduzido por pessoas leigas, "que tiram as mais variadas ilações do quadro verificado". A permanência do réu algemado indica, à primeira visão, cuidar-se de criminoso da mais alta periculosidade, desequilibrando o julgamento a ocorrer, ficando os jurados sugestionados". Quanto a essa questão do Tribunal do Júri, o STF já havia apreciado no Habeas Corpus (71.195-2/SP), relatado pelo Ministro Francisco Rezek, em que decidiu que a utilização de

${ }^{37}$ FUDOLI, Rodrigo de Abreu. Uso de Algemas: a Súmula Vinculante $\mathrm{n}^{\circ} 11$ do STF. Revista Phoenix Magazine, São Paulo, ano V, nº XI, p. 38-42, 2008, p. 38. 
algemas em sessão de julgamento somente se justifica para a "ordem dos trabalhos e à segurança dos presentes", embora naquele caso se tivesse compreendido a utilização como necessária. Embora se utilize um conceito amplo e aberto como "a ordem dos trabalhos", exige-se como condição necessária para algemar que haja uma justificativa excepcional e, que não se trate a aposição de algemas de regra para as pessoas em julgamento.

Esse aspecto foi albergado pela Lei $n^{0} 11.689$, de 2008 que introduziu modificações no Tribunal do Júri, no $\S 3^{\circ}$ do art. 474: "Não se permitirá o uso de algemas no acusado durante o período em que permanecer no plenário do júri, salvo se absolutamente necessário à ordem dos trabalhos, à segurança das testemunhas ou à garantia da integridade física dos presentes."

Um dos aspectos que apareceu no debate da SV 11 no STF foi o da exposição pública dos presos. Para o Ministro Gilmar Mendes "estamos a falar da aposição da algema para os fins de exposição pública", ou seja, "algemar significa expor alguém na televisão nesta condição, ou prender significa hoje algemar e colocar alguém na televisão" ${ }^{\text {"38 }}$.

Vê-se que há uma íntima ligação nos casos decididos pelo STF e a exposição de pessoas algemadas. No entanto, ao formular o enunciado da súmula vinculante, não houve preocupação em precisar quais são os critérios para justificar as situações em que há o "receio de fuga" ou de "perigo à integridade física própria ou alheia", por parte do preso ou de terceiros, para preencher a extrema vagueza para a formação desses $\operatorname{casos}^{39}$.

Há, com base nesses precedentes em que se discutiram prerrogativas inerentes ao cargo, a formulação de uma acusação de que essa súmula vinculante tenha como escopo evitar que pessoas detentoras de função pública proeminente fiquem expostas na mídia. Outro espectro de tal objeção seria a reprodução da maléfica seletividade processual e social que vivemos no Brasil.

A dignidade da pessoa humana de um banqueiro, de um conselheiro de Tribunal de Contas, de um procurador de justiça, de um desembargador ou de um pedreiro é a mesma ${ }^{40}$, pois todas as pessoas têm direito a não serem expostas como uma pessoa perigosa, exceto quando haja elementos concretos que autorizem tal conclusão.

Assim a SV 11 tem uma função didática, pois antes de se evitar uma multiplicação de processos, buscou-se "educar" os aplicadores na tarefa de

\footnotetext{
${ }^{38}$ SUPREMO TRIBUNAL FEDERAL. Debates e Aprovação da Súmula Vinculante $n^{\circ} 11$, a qual foi editada na Sessão Plenária de 13 de agosto de 2008 e foi publicada no DJE de 11.11.2008. Disponível em http://www.stf.jus.br/arquivo/cms/jurisprudenciaSumulaVinculante/anexo/DJE_ 11.11.2008.pdf. Acesso em 29 abr. 2013 - grifo nosso.

${ }^{39}$ FUDOLI, Rodrigo de Abreu. Uso de Algemas: a Súmula Vinculante $\mathrm{n}^{\circ} 11$ do STF. Revista Phoenix Magazine, São Paulo, ano V, nº XI, p. 38-42, 2008, p. 39.

${ }^{40}$ SELL, Sandro César. O Pedreiro, o Banqueiro e um par de Algemas. Jus Navegandi. Teresina, ano 12, $\mathrm{n}^{\circ}$ 1875, 19.08.2008. Disponível em: http://jus2.uol.com.br/doutrina/texto.aps?id=11618>. Acesso em 12 fev. 2013.
} 
não-exposição de pessoas algemadas. Isso porque, uma das funções para as quais as súmulas foram pensadas (não apenas as súmulas vinculantes) é a de orientação e de informação, para que se pudesse tomar conhecimento da jurisprudência, superando um dos obstáculos do acesso à justiça que é informar a posição do Tribunal a respeito de uma determinada matéria ${ }^{41}$.

Para entender, no entanto, a eficácia e a efetividade do enunciado sumular é preciso compreender como se comportam o STF e as instâncias ordinárias na sua aplicação. Observação que ganha especial relevo em se considerando a diversidade de casos sobre as quais se assentou a sua formulação.

Nesse escopo, a exigência da fundamentação escrita, se apresenta como requisito formal que permite controlar a utilização das algemas.

E, também com o fito de controle, o enunciado comina, além das responsabilidades administrativa, penal e civil, a sanção mais drástica: a nulidade da prisão ou do ato processual a que se refere", embora não se esclareça qual a natureza desta nulidade, se absoluta ou relativa ${ }^{42}$.

Para tentar compreender a extensão da referida súmula vamos recorrer ao sistema que é previsto para garantir sua aplicação, iniciando pelo instrumento que reforça o sentido vinculante.

\section{A APLICABILIDADE DA SÚMULA DAS ALGEMAS}

A reclamação constitucional é a ação constitucional que tem por objetivo preservar a competência e garantir a autoridade das decisões do STF (art. 102, I, "I", da CF/88), bem como evitar que ato administrativo ou decisão judicial contrariem ou apliquem indevidamente a Súmula Vinculante (art. 103-A, § $3^{\circ}$ da CF).

Para utilizar a reclamação em decisão de casos judiciais, basta alegar a ocorrência de contrariedade ou de uso indevido. A reclamação é a forma por excelência para garantir a obediência ao enunciado vinculante, pois os outros meios complementares de recursos e de impugnação continuam à disposição das partes (art. $7^{\circ}$ da Lei 11.417/2006). Em face disso, realizou-se uma pesquisa no sistema de busca do site ${ }^{43}$ do Supremo Tribunal Federal, utilizando como critério de busca: Súmula Vinculante $\mathrm{n}^{\circ} 11$ e Reclamação Constitucional.

Salienta-se que, da referida pesquisa, se obteve três acórdãos, uma ementa destacada de um informativo e cem decisões monocráticas. Os três acórdãos julgados (Rcl 8712/RJ, Rcl 7814/RJ e Rcl 9468 AgR/RJ) e a ementa

\footnotetext{
${ }^{41}$ SARLET, Ingo Wolfgang; WEINGARTNER NETO, Jayme. Dignidade da Pessoa Humana e o Uso de Algemas: uma proposta para uma adequada compreensão da extensão e eficácia da Súmula Vinculante $\mathrm{n}^{\circ} 11$ do STF. In: Revista de Estudos Criminais, Porto Alegre: Notadez, v. 11, $\mathrm{n}^{\circ}$ 50, jul./set. 2013. p. 67-68.

${ }^{42}$ SARLET, Ingo Wolfgang; WEINGARTNER NETO, Jayme. Dignidade da Pessoa Humana e o Uso de Algemas: uma proposta para uma adequada compreensão da extensão e eficácia da Súmula Vinculante $\mathrm{n}^{\circ} 11$ do STF. In: Revista de Estudos Criminais, Porto Alegre: Notadez, v. 11, $\mathrm{n}^{\circ}$ 50, jul./set. 2013. p. 69.

${ }^{43}$ SUPREMO TRIBUNAL FEDERAL - www.stf.jus.br/portal/jurisprudencia. Acesso em 10 mar. 2013.
} 
contida no Informativo $\mathrm{n}^{\circ} 588$ foram no sentido da improcedência da reclamação constitucional e da legalidade do uso das algemas.

Quanto às decisões proferidas em decisões monocráticas (cem decisões ${ }^{44}$ ), não foi possível localizar julgados que tivessem concedido a medida cautelar para relaxar a prisão ou que tivessem dado provimento à reclamação para anular o ato relativo à prisão realizada com o uso de algemas.

Para demonstrar objetivamente os fundamentos das decisões monocráticas dos Ministros do Supremo Tribunal Federal suprarreferidas, elaborou-se um quadro com o principal fundamento de cada decisão que negou seguimento, que não concedeu a medida cautelar ou que julgou monocraticamente a reclamação constitucional, o qual se reproduz a seguir:

\begin{tabular}{|c|c|}
\hline Fundamentação da Decisão Monocrática & Número de Decisões \\
\hline Falta de comprovação do uso das algemas & 10 \\
\hline $\begin{array}{c}\text { Existência de decisão por escrito e fundamentada para o uso } \\
\text { das algemas }\end{array}$ & 47 \\
\hline Resistência e receio de fuga do preso & 23 \\
\hline Periculosidade do preso & 20 \\
\hline
\end{tabular}

Registra-se que quase metade das decisões monocráticas das reclamações constitucionais aponta que não era cabível essa ação constitucional ou ela era improcedente, pois havia nos autos uma decisão escrita e fundamentada para o uso das algemas. Além disso, outra metade das decisões motiva a improcedência da reclamação nos termos vagos do receio de fuga e da periculosidade do preso.

Portanto, em nenhuma das cem decisões monocráticas, houve 0 reconhecimento de que as algemas foram utilizadas de forma inadequada e desnecessária. É interessante que o STF, na maioria dos casos, tenha se contentado com o critério formal (decisão escrita), o que pode ser decorrência (a) de que há uma estreiteza da cognição da reclamação ${ }^{45}$; (b) de que não há contrariedade ou aplicação indevida; (c) de que, se houve contrariedade ou aplicação indevida, ela foi sanada nas instâncias ordinárias, na sede recursal apropriada ou (d) que a avaliação do STF é apenas formal. Saliente-se que estas hipóteses não são excludentes entre si, mas se complementam.

\footnotetext{
${ }^{44}$ Exemplifica-se a análise das Reclamações Constitucionais: Rcl 15199 MC/SP, Min. Celso de Mello, Decisão Monocrática proferida em 01.03.2013.

${ }^{45}$ Neste sentido são exemplos a o Rcl 10479, a RCL no 6.870/GO, decisão monocrática, Relatora Ministra Ellen Gracie, DJ de 06.11.2008 rança dos presentes à audiência, tendo em vista as peculiaridades do local. 3. De acordo com a jurisprudência da Corte, não é "possível admitir-se, em sede de reclamação, qualquer dúvida a respeito das questões de fato apontadas pela Juíza para negar o pedido da defesa de retirada das algemas do reclamante".
} 
De fato, há casos em que parece que há justificativa plausível, como o caso de acusado ligado à facção criminosa (HC 103003/SP), mas em outros casos aparece uma justificativa - cumulada ou solitária - de falta de pessoal de segurança que já havia sido rechaçada quando foram estabelecidos os precedentes da súmula vinculante (HC 91.952), como, por exemplo, as Rcl 8712/RJ e AG. REG. Rcl.628/SP.

Há casos que pela sua notoriedade se sobrepõe às provas nos autos. A análise das ações de reclamação constitucional vem reforçar que a súmula vinculante da limitação do uso das algemas foi editada para responder aos casos de pessoas famosas que estavam sendo processadas no ano de $2008^{46}$ e que foram expostas na mídia, ao serem presas, algemadas.

Para complementar a pesquisa na jurisprudência do Supremo Tribunal Federal, realizou-se a busca utilizando, apenas, o termo algemas e se obteve vinte acórdãos e 181 decisões monocráticas, cujas decisões são no sentido de que não houve qualquer afronta às normas constitucionais, ao ser empregado o uso das algemas ${ }^{47}$, o que dá indicações dos limites da cognição do STF para a aplicação da sua súmula.

O sistema sumular vinculante possui um sistema complementar de defesa, ancorado nos demais órgãos do judiciário. Há uma série de ações constitucionais, recursos ordinários, extraordinários e a reclamação que se complementam e que assumem a tarefa de realizar os valores constitucionais. A reclamação não é única técnica utilizada para que a súmula vinculante seja aplicada devidamente (ou não contrariada), especialmente quando se verifica que o STF tem se contentado apenas com a exigência formal de que haja justificativa por escrito ${ }^{48}$.

A utilização das algemas deve ser fundamentada com as peculiaridades do destinatário da decisão penal e também do caso. Os destinatários da SV 11 que são os policiais (especialmente as autoridades policiais), agentes do sistema prisional, agentes sócio-educativos e os magistrados devem motivar

\footnotetext{
${ }^{46}$ Como pode ser observado dos debates para a aprovação da Súmula Vinculante $\mathrm{n}^{\circ} 11$ relativa à limitação ao uso das algemas, o Ministro Gilmar Ferreira Mendes - Presidente do Supremo Tribunal Federal no ano de 2008 - apontou que "Na verdade, quando estamos a falar hoje desta questão da algema, na prática brasileira, estamos a falar da aposição da algema para os fins de exposição pública" e quem é, geralmente, exposto na mídia? Ver: SUPREMO TRIBUNAL FEDERAL. Debates e aprovação da Súmula Vinculante $n^{\circ} 11$, a qual foi editada na Sessão Plenária de 13.08.2008. Disponível em: http://www.stf.jus.br/arquivo/cms/jurisprudenciaSumulaVinculante/ anexo/ DJE_11.11.2008.pdf. Acesso em 29 abr. 2013 - grifo nosso.

${ }^{47}$ Exemplifica-se a busca jurisprudencial do STF com o julgamento da Rcl 15047-SP (Julgada em 06.12.2013); do ARE 781381-DF (Julgado em 11.11.2013) e do HC 116487-PR (Julgado em 25.02.2013). Pesquisa realizada no site do STF - Supremo Tribunal Federal. Disponível em http://www. stf.jus.br/portal/jurisprudencia/listarJurisprudencia.asp?s1=\%28\%28algemas\%29\%29+NAO+S.PRES. \&pagina=3\&base=baseMonocraticas\&url=http://tinyurl.com/d8w5pqw. Acesso em 29 dez. 2013.

${ }^{48}$ Neste sentido pode-se verificar: "Não é possível admitir-se, em reclamação, qualquer dúvida a respeito das questões de fato apontadas pela juíza para determinar o uso das algemas durante a realização das audiências". Rcl 6.870 (DJe 06.11.2008), Relatora Ministra Ellen Gracie, Decisão Monocrática.
} 
sua decisão levando em consideração características pessoais do preso ${ }^{49} \mathrm{e}$ não os aspectos abstratos do tipo penal que a pessoa foi acusada de infringir, lógica que é similar aos precedentes do STF e STJ quanto à motivação de decisões que decretam ou mantém a prisão provisória no curso do processo.

A decisão que determina o uso das algemas pode utilizar a forma como o crime foi executado, como, por exemplo: latrocínio com violência ou extorsão mediante sequestro com lesão grave à vítima. Tais circunstâncias, que indicam a periculosidade do custodiado, justificariam o uso excepcional das algemas, sendo, assim, uma característica especial apta a motivar o emprego desse instrumento.

Assim, compete ao operador do direito analisar se o ato das autoridades ou decisão judicial que determinou a prisão com o uso das algemas utilizou uma fundamentação genérica ou se motivou a decisão com base nos aspectos pessoais do preso ou em outros relativos à forma como o crime foi praticado (periculosidade do agente).

O STJ aprecia essa matéria, o que significa que essas alegações também são reproduzidas em instâncias ordinárias, porque objeto de recurso. $\mathrm{Na}$ pesquisa realizada no site do Superior Tribunal de Justiça - STJ, cuja matéria (prisão ilegal - uso indevido das algemas) pode chegar a essa Corte Superior pelo meio do habeas corpus e do recurso especial, percebe-se que não tem sido reconhecida a ofensa à Súmula Vinculante $n^{\circ} 11$, pois a excepcionalidade foi considerada adequadamente motivada nas decisões atacadas $^{50}$, principalmente em situações de perigo à integridade e segurança dos presentes e da periculosidade do réu ${ }^{51}$. Também há alegação da insuficiência probatória quanto à demonstração da utilização indevida das algemas em razão da estreiteza da cognição das ações constitucionais ${ }^{52}$.

49 SCHEID, Carlos Eduardo. A Motivação das Decisões Penais a partir da Teoria Garantista. Porto Alegre: Livraria do Advogado, 2009, p. 107-108.

${ }^{50}$ Exemplifica-se a jurisprudência do Superior Tribunal de Justiça - STJ, através do julgamento do RHC 39.729-SP, $5^{a}$ Turma, Rel. Min. Moura Ribeiro, julgado 03.09.2013.

${ }^{51}$ A jurisprudência do Superior Tribunal de Justiça - STJ pode ser visualizada através do julgamento do HC 2344684-SP, 6a Turma, Rel. Min. Og Fernandes, julgado 20.08.2013: "3. O uso de algemas durante a sessão de julgamento do Tribunal do Júri ficou devidamente justificada em razão da periculosidade do réu - já condenado por homicídio anteriormente -, do seu desaparecimento por 16 anos após fugir da cadeia local em que esperava a realização do julgamento e da impossibilidade de se garantir a segurança dos presentes à sessão reconhecida pelo chefe da escolta policial.(...).

52 PROCESSO PENAL. HABEAS CORPUS. ANTIGA FIGURA DA QUADRILHA ARMADA. (1) WRIT IMPETRADO COMO SUCEDÂNEO RECURSAL. IMPROPRIEDADE DA VIA ELEITA. (2) ALEGAÇÃO DE INDEVIDA SUJEIÇÃO DO PACIENTE AO EMPREGO DE ALGEMAS. INSTRUÇÃO. DEFICIÊNCIA. ORDEM NÃO CONHECIDA. 1. No contexto de racionalização do emprego do habeas corpus, é inadmissível a sua utilização como sucedâneo recursal. 2. A alegação de que teria havido ilícita sujeição do paciente ao uso de algemas pressupõe a sua demonstração por meio de prova pré-constituída. Descumprido tal tarefa, de bem aparelhar a petição do mandamus, tem-se clara hipótese de incidência do ônus objetivo da prova, pelo qual, diante de situação em que há insuficiência/inexistência de elemento da prova, passa-se a perquirir sobre o ônus da prova subjetivo, ou seja, a quem caberia a produção da prova pré-constituída do 
Outra discussão é a da natureza da nulidade - se absoluta ou relativa que foi cominada para a utilização indevida de algemas ${ }^{53}$, que no último dependeria da alegação - não se admitindo o conhecimento de ofício - e de demonstração de prejuízo causado ao acusado. Assim, como as alegações de nulidade têm aparecido posteriormente, o Superior Tribunal de Justiça tem exigido a demonstração de prejuízo sofrido, em consonância com o princípio pas de nullité sans grief, preceituando que seja alegado na primeira ocasião em que se falou nos autos ${ }^{54}$.

Esta nova questão demonstra como careceu de amadurecimento o enunciado sumular e de como o seu teor pode propiciar a sua (re)leitura pelas

constrangimento ilegal. Tocando ao impetrante tal incumbência, com a insuficiência probatória, a este recai a desvantagem processual. 3. Ordem não conhecida. (HC 235.534/SP, Rel. Ministra Maria Thereza de Assis Moura, Sexta Turma, julgado em 22.04.2014, DJe 30.04.2014).

${ }_{53}$ Ingo Wolfgang Sarlet e Jayme Weingartner Neto lecionam que o alcance da nulidade decorrente do uso das algemas deve ser aplicado com prudência, pois entendem que o uso das algemas em audiências de instrução e julgamento de processos que não sejam da competência do Tribunal de Júri foram um terceiro grupo de situações em que se analisa o descumprimento do uso desse instrumento e ditos autores apontam que a nulidade nesse grupo deve ser relativa e deve ser arguida pela defesa no momento processual adequado e com a demonstração do efetivo prejuízo. "A possibilidade de prejuízo, que não é inexorável, justifica o ônus da parte em levantar e controverter a situação humilhante, que não resulta, no caso, da mera utilização das algemas, mas na falta de necessidade e correspondente justificação das algemas, mas na falta de necessidade e correspondente justificação pela autoridade. A ausência de fundamentação, por sua vez, não implica automática nulidade processual, mas configura, por si, violação da súmula e acarreta eventual responsabilização do binômio Estado/órgão jurisdicional. Aliás, em relação ao magistrado, que descumpriu dever formal de fundamentação axiologicamente reforçado, deveria haver, mesmo na ausência de prejuízo processual, verificação pelos órgãos de correição, pelo menos no sentido de orientação. Por outro lado, a liberdade do preso, em caso de anulação da sentença e da audiência de instrução e julgamento, deverá ser reavaliada, diante dos vetores do art. 312 do CPP e da duração razoável do processo (CF, art. 5, LXXXVIII). As diretrizes aventadas, ao menos é o que se sustenta, coadunam-se com vertente majoritária doutrina e da práxis jurisprudencial e realizam harmonização adequada dos valores em conflito na questão das algemas" SARLET, Ingo Wolfgang; WEINGARTNER NETO, Jayme. Dignidade da Pessoa Humana e o Uso de Algemas: uma proposta para uma adequada compreensão da extensão e eficácia da Súmula Vinculante $\mathrm{n}^{\circ} 11$ do STF. In: Revista de Estudos Criminais. Porto Alegre: Notadez, v. 11, no 50, jul./set. 2013. p. 72.

${ }^{54}$ Como é ilustrativo a seguinte ementa: PENAL E PROCESSO PENAL. AGRAVO REGIMENTAL NO AGRAVO EM RECURSO ESPECIAL. VIOLAÇÃO AOS ARTS. 571, II E VIII, E 563, AMBOS DO CPP. NULIDADE PELO USO DE ALGEMAS NA AUDIÊNCIA DE INSTRUÇÃO E JULGAMENTO. (I) - PRECLUSÃO. ACÓRDÃO EM CONFORMIDADE COM A JURISPRUDÊNCIA DESTA CORTE. SÚMULA 83/STJ. (II) - AUSÊNCIA DE DEMONSTRAÇÃO DE PREJUÍZO. PAS DE NULLITÉ SANS GRIEF. AGRAVO REGIMENTAL A QUE SE NEGA PROVIMENTO. 1. Este Tribunal sufragou o entendimento no sentido de que "a teor do art. 571, II, do CPP, as nulidades da instrução criminal, nos processos de competência do juiz singular, devem ser arguidas, em preliminar, na oportunidade do oferecimento das alegações finais, sob pena de preclusão". (HC 168.984/GO, Rel. Min. Assusete Magalhães, Sexta Turma, DJe 21.05.2013). Incidência do enunciado $n^{\circ} 83$ da Súmula desta Corte. 2. Segundo a legislação processual penal em vigor, é imprescindível quando se trata de nulidade de ato processual a demonstração do prejuízo sofrido, em consonância com o princípio pas de nullité sans grief, o que não ocorreu na espécie. 3. Agravo regimental a que se nega provimento. (AgRg no AREsp 342.853/SC, Rel. Ministra Maria Thereza de Assis Moura, Sexta Turma, julgado em 01.04.2014, DJe 14.04.2014) 
instâncias ordinárias, não gerando a necessária previsibilidade que as súmulas - com especialmente ênfase às vinculantes, devem construir.

Este debate está presente em decisões e julgados de diversos órgãos fracionários do Tribunal de Justiça do Estado do Rio Grande do Sul, o que demonstra esta falta de amadurecimento. Algumas decisões de órgãos fracionários desse Tribunal têm decretado a nulidade de ofício de atos processuais realizados com réu algemados, pois entende que a utilização desse instrumento gera a presunção de culpabilidade e imputa periculosidade ao preso que está algemado $5^{5}$, especialmente quando não há qualquer referência no termo de Audiência.

No entanto, outro grupo de decisões tem sido mais incisivo em reconhecer a nulidade como relativa ou, em se satisfazer com critérios formais de justificativa. Os julgados proferidos pelo Tribunal de Justiça do Estado do Rio Grande do Sul apontam, nominalmente, aceitação do uso das algemas como excepcional, ressalvando que esse instrumento continua sendo permitido, quando estiverem presentes os requisitos fáticos previstos na súmula vinculante e, especialmente, quando a decisão judicial motivar a necessidade do uso das algemas ${ }^{56}$.

No julgamento da Apelação Crime $\mathrm{n}^{0} 70055732165$, a ratio decidendi para afastar a alegação de nulidade do julgamento de um roubo duplamente majorado foi no sentido de que o uso das algemas não foi vedado, mas apenas restringido. A decisão a quo estava devidamente justificada: a necessidade de garantir a segurança das pessoas que estavam na sala de audiência, em virtude da periculosidade do réu.

Finalmente cabe assinalar que já há registros de indenizações imputadas ao Estado pelo uso indevido de algemas independentemente da nulidade dos atos penais ${ }^{57}$, o que demonstra a utilização das outras vias propostas no referido enunciado.

\footnotetext{
${ }^{55}$ RECURSO EM SENTIDO ESTRITO. HOMICÍDIO QUALIFICADO. PRONÚNCIA. RECURSO QUE VISA IMPRONÚNCIA, ABSOLVIÇÃO SUMÁRIA OU DESCLASSIFICAÇÃO PARA TIPO PENAL QUE NÃO DA COMPETÊNCIA DO TRIBUNAL DO JÚRI. NULIDADES POR AUSÊNCIA DO MINISTÉRIO PÚBLICO NA AUDIÊNCIA DE INSTRUÇÃO E POR INOBSERVÂNCIA DA SÚMULA VINCULANTE N ${ }^{\circ} 11$ DO STF, QUE VÃO DECLARADAS DE OFÍCIO. Violação ao disposto no artigo 564, inciso III, letra "d", do Código de Processo Penal e aos princípios constitucionais do devido processo legal e do sistema acusatório. A ausência do Ministério Público gera grave distorção no processo, que se transforma em inquisitório, uma relação linear entre Juiz e réu, e traz evidente prejuízo para este. Réu que é interrogado algemado. Ausência de justificativa para a não retirada das algemas na solenidade. Verificada a inobservância ao disposto na Súmula Vinculante $n^{\circ} 11$ do STF, impõe-se a desconstituição da sentença e dos atos praticados, determinando-se a reabertura da instrução. DISPOSIÇÕES DE OFÍCIO. PRISÃO MANTIDA. RECURSO PREJUDICADO. Recurso em Sentido Estrito no 70054386834, Terceira Câmara Criminal, Tribunal de Justiça do RS, Relator: Des. João Batista Marques Tovo, Julgado em 19.09.2013.

${ }^{56}$ Apelação Crime $n^{\circ} 70055762165$, Oitava Câmara Criminal, Tribunal de Justiça do RS, Relatora: Des $^{\mathrm{a}}$. Fabianne Breton Baisch, Julgado em 06.11.2013.

${ }^{57}$ Exemplifica-se a responsabilidade civil do estado pelo uso indevido da algema pelo julgamento
} 


\section{CONSIDERAÇÕES FINAIS}

A Súmula Vinculante $n^{\circ} 11$ cumpre a importante função de destacar para os agentes públicos a visão do STF no resguardo dos direitos fundamentais da presunção de inocência e dignidade da pessoa humana. Ele regula o uso das algemas, no sentido de uma utilização apenas excepcional e mediante justificativa escrita.

No entanto, se mostrou que as situações em que se fazem presentes os requisitos "de fundado receio de fuga" ou de "perigo à integridade física própria ou alheia" por parte do preso ou de terceiros não estão esclarecidas de forma suficiente, nem na súmula vinculante, nem nos precedentes que a originaram. No mesmo sentido, se registrou que tais conceitos indeterminados ainda não foram elucidados nos casos posteriores à edição da súmula.

Há, por conseguinte, uma evidente insuficiência da jurisdição do STF exercida por meio da reclamação constitucional, do habeas corpus e do recurso extraordinário, Isso, em função de uma análise muito restrita, que geralmente avalia a presença de uma justificação, apenas do ponto de vista formal (decisão escrita de autoridade) que indica o cumprimento dos pressupostos permissivos da utilização das algemas. Avaliar os elementos fáticos de utilização da súmula e produzir standards mais seguros é o grande desafio a ser satisfeito pela jurisdição constitucional.

Os dados fáticos são de difícil controlabilidade e demonstram a insuficiência de balizas seguras para o escrutínio da utilização das algemas. Nos casos apreciados pelo STF, bem como na jurisdição dos demais órgãos do poder judiciário, o uso indevido das algemas gera nulidade relativa, exigindo a demonstração de prejuízo. Tal postura denota perigo para a própria autoridade do STF, notadamente em razão da utilização de em um enunciado sumular recheado de conceitos indeterminados e que não foram suficientemente amadurecidos nos precedentes que antecederam a sua edição.

Isso evidencia o papel complementar dos demais órgãos do Poder Judiciário, no sentido de continuar a obra iniciada pelo STF, para que efetivamente o princípio da presunção de inocência e da dignidade da pessoa humana ganhem vida. Esse papel é extremamente importante para que não se gere discriminação na aplicação da súmula ou ao menos uma discriminação indireta, não intencional, mas sempre presente ${ }^{58}$, reproduzindo a seletividade social e de raça existente no sistema penal geral.

da Apelação Cível no 70055373377, Nona Câmara Cível, Tribunal de Justiça do RS, Relatora: Des $^{\mathrm{a}}$. Iris Helena Medeiros Nogueira, Julgado em 11.09.2013.

${ }_{58}$ RIOS, Roger Raupp. Direito da Antidiscriminação: discriminação direta, indireta e ações afirmativas. Porto Alegre: Livraria do Advogado Editora, 2008. A discriminação, conforme o mencionado autor, a partir dos tratados internacionais pode ser conceituada como "qualquer distinção, exclusão, restrição ou preferência que tenha o propósito ou o efeito de anular ou prejudicar o reconhecimento, gozo ou exercício em pé de igualdade de direitos humanos e liberdades fundamentais nos campos econômico, social, cultural ou em qualquer campo da vida pública." (RIOS, Roger Raupp. Direito da Antidiscriminação: p. 20). Segundo o autor a discriminação 


\section{REFERÊNCIAS BIBLIOGRÁFICAS}

ALEXY, Robert. Teoria dos Direitos Fundamentais. Traduzida por Virgílio Afonso da Silva, 2. ed., São Paulo: Malheiros, 2011.

ALVIM, Arruda. Tratado de Direito Processual Civil. 2. ed., refundida do Código de Processo Civil comentado. v. 1 (Arts. $1^{\circ}$ ao $6^{\circ}$ ). São Paulo: Editora Revista dos Tribunais, 1990.

ÁVILA, Humberto. Teoria dos Princípios. 12. ed., São Paulo: Malheiros, 2011.

CAMARGO, Virgínia. Realidade do Sistema Prisional no Brasil. Disponível em: http://www.ambito-juridico.com.br/site/index.php?n_link=revista_artigos_leitura\&artigo_id =1299. Acesso em 08 nov. 2013.

CARNELUTTI, Francesco. As Misérias do Processo Penal. Traduzida por José Antônio Cardinalli. 6. ed., Campinas: Bookseller, 2005.

FUDOLI, Rodrigo de Abreu. Uso de Algemas: a Súmula Vinculante $\mathrm{n}^{0} 11$ do STF. Revista Phoenix Magazine, São Paulo, ano V, nº XI, p. 38-42, 2008.

GOMES FILHO, Antonio Magalhães. Presunção de Inocência e Prisão Cautelar. São Paulo: Saraiva, 1991.

GUEDES, Clarissa Diniz. Presunção de Inocência, Liberdade de Expressão e Direito à Informação: reflexões à luz da jurisprudência do Tribunal Europeu de Direito Humanos e da Corte Americana de Direitos Humanos. Revista Forense, Rio de Janeiro: Forense, vol. 411, set./out. 2010.

LEAL, João José; DECOMAIN, Pedro Roberto. Súmula Vinculante, Regras de Reconhecimento e Textura aberta do Direito. Resenha Eleitoral, v. 11, no 1, p. 39, jan./jun. 2004.

MANCUSO, Rodolfo de Camargo. Divergência Jurisprudencial e Súmula Vinculante. 2. ed., São Paulo: Revista dos Tribunais, 2001.

MENDES, Gilmar Ferreira; COELHO, Inocêncio Mártires; BRANCO, Paulo Gustavo Gonet. Curso de Direito Constitucional. 4. ed., São Paulo: Saraiva, 2009.

MIRANDA, Jorge. Manual de Direito Constitucional: actividade constitucional do Estado. T. 5, Coimbra: Coimbra Editora, 2000.

MORAES, Maurício Zanoide de. Presunção de Inocência no Processo Penal Brasileiro: análise de sua estrutura normativa para elaboração legislativa e decisão judicial. Rio de Janeiro: Lumen Juris, 2010.

MÜLLER, Friedrich. Métodos de Trabalho do Direito Constitucional. 3. ed., rev. e ampl. Rio de Janeiro: Renovar, 2005.

PITOMBO, Sérgio Marcos de Moraes. Emprego de Algemas - notas em prol de sua regulamentação. Revista dos Tribunais, São Paulo, v. 592, p. 275-292, fev. 1985.

direta pode se dar de três modos: discriminação explícita, discriminação na aplicação do direito e discriminação na concepção do direito. Exemplo de discriminação na aplicação do direito dar-se-ia no caso de agentes policiais que, quando da abordagem de um conjunto de indivíduos, promovessem, deliberadamente, buscas pessoais (revistas) somente em relação a pessoas negras, ou aplicassem de forma mais rigorosa a legislação em relação a estes. Caso se entenda que não há uma discriminação direta, mas indireta, ou seja, como tendo o "o efeito de", uma vez que a distinção, exclusão, restrição ou preferência podem não só decorrer do "propósito", mas também podem ter "o efeito de" (involuntário) anular ou prejudicar o reconhecimento, gozo ou exercício, em pé de igualdade, de direitos e liberdades. 
REIS, Mauricio Martins. Precedentes Obrigatórios e sua Adequada Interpretação. In: Revista do Programa de Pós-Graduação em Direito da Universidade Federal da Bahia, Salvador: UFBA, jul. 2014.

RIOS, Roger Raupp. Direito da Antidiscriminação: discriminação direta, indireta e ações afirmativas. Porto Alegre: Livraria do Advogado Editora, 2008.

ROSAS, Roberto. Direito Sumular: comentários às Súmulas do Supremo Tribunal Federal e do Superior Tribunal de Justiça. 8. ed., rev. e atual. São Paulo, Malheiros Editores, 1997.

SARLET, Ingo Wolfgang. Dignidade da Pessoa Humana e Direitos Fundamentais. Porto Alegre: Livraria do Advogado, 2008.

Notas sobre a Dignidade da Pessoa Humana na Jurisprudência do STF. In.

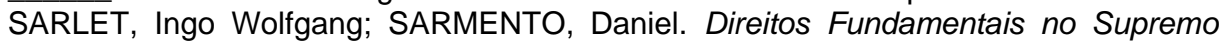
Tribunal Federal: Balanço e Crítica. Rio de Janeiro: Lumen Juris, 2011.

SARLET, Ingo Wolfgang; WEINGARTNER NETO, Jayme. Dignidade da Pessoa Humana e o Uso de Algemas: uma proposta para uma adequada compreensão da extensão e eficácia da Súmula Vinculante $\mathrm{n}^{\mathrm{0}} 11$ do STF. In: Revista de Estudos Criminais. Porto Alegre: Notadez, v. 11, nº 50, jul./set. 2013.

SCHÄFER, Gilberto. Súmulas Vinculantes - Análise crítica da experiência do Supremo Tribunal Federal. Porto Alegre: Livraria do Advogado, 2012.

A Atividade de Pretor Romano: antecedentes remotos do processo de sumularização. In: Revista da AJURIS, Porto Alegre: AJURIS, v. 140, nº 132, dez. 2013.

SCHAUER, Frederick. Precedent. Stanford Law Review, fev. 1987. Disponível em: <http://www.gvpt.umd.edu/CITE-IT/Documents/Schauer\%201987\%20Precedent.pdf>. Acesso em: 20 nov. 2013.

SCHEID, Carlos Eduardo. A Motivação das Decisões Penais a partir da Teoria Garantista. Porto Alegre: Livraria do Advogado, 2009.

SELL, Sandro César. O Pedreiro, o Banqueiro e um par de Algemas. Jus Navegandi. Teresina, ano 12, no 1875, 19.08.2008. Disponível em: http://jus2.uol.com.br/doutrina/ texto.aps?id=11618>. Acesso em 12 fev. 2013.

SILVA, Celso Albuquerque. Do Efeito Vinculante: sua legitimação e aplicação. Rio de Janeiro: Lumen Juris, 2005.

STF. Debates e Aprovação da Súmula Vinculante $n^{\circ} 11$, a qual foi editada na Sessão Plenária de 13 de agosto de 2008 e foi publicada no DJE de 11.11.2008. Disponível em: http://www.stf.jus.br/arquivo/cms/jurisprudenciaSumulaVinculante/anexo/DJE_ 11.11.2008.pdf. Acesso em 29 abr. 2013.

THOMÉ, Liane Maria Busnello. Dignidade da Pessoa Humana e Mediação Familiar. Porto Alegre: Livraria do Advogado, 2010.

VIERA, Luís Guilherme. Algemas: uso e abuso. Revista Síntese de Direito Penal e Processual Penal. São Paulo, nº 16, p. 11-16, out./nov. 2002.

VIEIRA, Oscar Vilhena. Supremocracia. Revista Direito GV, São Paulo 4(2), p. 441-464, jul./dez. 2008, p. Revista de Direito do Estado, Rio de Janeiro, v. 3, no 12 , p. 55-75, out./dez. 2008, p. 445.

ZAVASCKI, Teori Albino. Eficácia das Sentenças na Jurisdição Constitucional. São Paulo: Revista dos Tribunais, 2001. 